\title{
A Systematic Review on Automatic Detection of Plasmodium Parasite
}

\author{
Amin Siddiq Sumi, Hanung Adi Nugroho*, Rudy Hartanto \\ Department of Electrical and Information Engineering, Faculty of Engineering, Universitas Gadjah Mada, \\ Yogyakarta, Indonesia \\ Received 07 July 2020; received in revised form 27 September 2020; accepted 21 January 2021 \\ DOI: https://doi.org/10.46604/ijeti.2021.6094
}

\begin{abstract}
Plasmodium parasite is the main cause of malaria which has taken many lives. Some research works have been conducted to detect the Plasmodium parasite automatically. This research aims to identify the development of current research in the area of Plasmodium parasite detection. The research uses a systematic literature review (SLR) approach comprising three stages, namely planning, conducting, and reporting. The search process is based on the keywords which were determined in advance. The selection process involves the inclusion and exclusion criteria. The search yields 45 literatures from five different digital libraries. The identification process finds out that 28 methods are applied and mainly categorizes as machine learning algorithms with performance achievements between $60 \%$ and $95 \%$. Overall, the research of Plasmodium parasite detection today has focused on the development with artificial intelligence specifically related to machine and deep learning. These approaches are believed as the most effective approach to detect Plasmodium parasites.
\end{abstract}

Keywords: systematic literature review, Plasmodium parasite, malaria, machine learing

\section{Introduction}

Malaria is a disease that has taken many lives in the world. According to the World Health Organization 2018 (WHO), there were 219 million cases of malaria in 2017; 435,000 of the cases ended with deaths [1]. The Plasmodium parasite is a cause of malaria that usually spreads to humans through the bite of a female Anopheles mosquito. This type of parasite will infect red blood cells and usually multiply in the human liver system [2]. To identify the phases and species of Plasmodium in general, paramedics observes the image of thin blood smears with the aid of a microscope [3]. However, this technique has some weaknesses such as blood staining techniques, the condition of the equipment, and the level of paramedic experience. These issues will potentially become obstacles. They will affect the objectivity of the results if the identification is made by microscope observation [4-5].

Alternative examinations with the help of computer-assisted automatic Plasmodium parasites have been widely proposed by several researchers, which ranges from conventional methods to those utilizing artificial intelligence through machine learning. The research on Plasmodium parasite detection currently has developed and attracted many researchers in the area of image processing, computer vision, and artificial intelligence. There are three main topics to cover, namely detection, classification, and segmentation. One of the most popular approaches among researchers is machine learning which is the sub-division of artificial intelligence. Machine learning algorithms utilize data as the main device to study existing patterns and then use data from the learning process to make decisions. This approach is deemed to be effective in solving tasks such as classification, detection, and segmentation because it produces an accurate result consistently.

* Corresponding author. E-mail address: adinugroho@ugm.ac.id

Tel.: +62-274-552305 
Some recent studies even suggest automatic ways of detecting Plasmodium parasites, such as research conducted by Nugroho [5] who detected Plasmodium parasites by using threshold techniques and morphological operations. The results of the experiment showed that the proposed method reached accuracy, sensitivity, specificity, prediction value positive and prediction value negative of $96.74 \pm 0.7075 \%, 76.77 \pm 2.1441 \%, 99.74 \pm 0.1397 \%, 97.84 \pm 1.2514 \%$ and $96.61 \pm 0.8021 \%$, respectively. Moreover, Setianingrum [6] identified the type of Plasmodium falciparum parasite with the gray level co-occurrence matrix (GLCM) to analyze parasite morphology by recognizing the texture and extraction of the morphological features of the parasite. The results achieved an accuracy of $91.67 \%$.

Furthermore, Yang [1] conducted similar research to automatically detect Plasmodium parasites by utilizing artificial intelligence through deep learning. The researcher used an intensity-based iterative global minimum screening. Also, to identify whether they were included as parasites or non-parasites, a convolutional neural network (CNN) was adjusted to perform candidate classification tasks. The results obtained the sensitivity of $92.59 \% \pm 1.27 \%$, specificity of $94.33 \% \pm 1.25 \%$, accuracy of $93.46 \% \pm 0.32 \%$, precision of $94.25 \% \pm 1.13 \%$, AUC of $98.39 \% \pm 0.18 \%$, and negative predictive value of $92.74 \% \pm 1.09 \%$.

A study conducted by Nayak [7] used a deep learning approach to detect the Plasmodium parasites. In this research, various models of deep learning were compared to investigate the model which offered the best accuracy. Some of the models included Densenet121, VGG16, Alexnet, Resnet50, FastAI, and Resnet101. The results showed that Resnet50 had the highest accuracy. Additionally, Prakash [8] in 2020 used the deep learning approach called CNN to predict the infection of the Plasmodium parasite from a thin blood smear. The CNN model was optimized towards overfitting and gained a score of more than $94 \%$ of F1.

Similar research was performed by Shekar [9] on three models of CNN, namely Basic CNN, Frozen CNN, and Fine-Tuned $\mathrm{CNN}$, to predict infected cells and to classify automatically from a thin blood smear. The researcher then compared the three models and gained the levels of accuracy of 94\% for Basic CNN, 92\% for Frozen CNN, and 96\% for Fine-Tuned CNN. Shah [10] also conducted similar research by using the CNN to detect and to classify the Plasmodium parasites. The proposed model consisted of three convolutional layers where each layer was fully interconnected. The results achieved the level of accuracy of 95\%. Based on several latest research works, an artificial intelligence approach based on machine learning and deep learning algorithms has been widely used and successfully obtained the level of accuracy, sensitivity, spesificity, and precision of more than $90 \%$.

With such rapid development and the number of studies, new researchers deal with challenges to find research gaps related to the topic of automatic detection systems on Plasmodium parasites. The rapid development will also have an impact on several studies in the future, for instance, the lack of contributions given due to the difficulty to find the latest research boundaries. Hence, a complete picture related to the current conditions of Plasmodium parasite detection research is missing. Likewise, the existing research needs to be collected and identified to express key aspects of research such as methods, generated performance, drawbacks, and benefits of the methods, datasets, and contribution.

This paper aims to identify the development of current research on the Plasmodium parasite detection system by conducting an in-depth study to examine several aspects such as research trends from year to year, the model of the approach used in solving the problems, the methods and performance produced, the dataset used in the research, and the contribution of every single study which is reviewed in this paper. The results of the review are expected to provide a general picture related to the research development in the field of the Plasmodium parasite. This paper is written with the following order. Section 2 discusses the review-based research works in the field of the Plasmodium parasite detection. The research methodology is explained in Section 3. Moreover, Section 4 discusses the results and answers from the research questions. Finally, Section 5 summarizes the key results of the research. 


\section{Related Work}

In this section, it discusses several review-based research in the field of the Plasmodium parasite detection. The literature review research on malaria diagnosis is not novel. Similar research has been conducted earlier, for example by Rosado [11] in 2016 who reviewed literature concerned with the detection and segmentation of the Plasmodium parasite for both blood seamers, namely thick blood and thin blood. The review process was carried out by collecting and examining various image processing methods and analysis approaches that have been proposed in several pieces of literature for the task of parasite detection and segmentation. In the research, the types of Plasmodium parasite species were also discussed, such as $\mathrm{P}$. falciparum, P.vivax, P.ovale, and P.malariae along with the stages of each parasite, namely Trophozoite, Schizont, and Gametocyte.

Furthermore, the same study was conducted by Jan [12] in 2017 to comprehensively review and analyze the detection of Plasmodium parasites. In the research, it reviewed several parts, namely the background of malaria, variations in species morphology and life stages of parasites, microscopic diagnostic methods, the general architecture of automatic malaria diagnosis, collection of techniques used by researchers in the automatic diagnosis of malaria, and performance comparisons obtained. The research also sheds light on the challenges and directions for future research in the field of detection of Plasmodium parasites.

Poostchi [13] also provided an overview of the techniques used by earlier researchers, which discussed recent developments in image analysis and machine learning for malaria diagnosis. The research focused on the review within the scope of image processing methods ranging from coloring techniques, image acquisition, preprocessing, segmentation techniques, feature extraction, and classification methods. In addition, in the review, it also discussed the latest developments in automatic malaria diagnosis, namely the emergence of a deep learning approach. Deep learning is believed to be able to automate old ways to be more efficient and have a superior level of performance when compared to image processing approaches.

Of the three literature review studies that have been described, the review method of some researchers still uses conventional techniques where the literature review framework is compiled by the author without any specific standards governing it. For this reason, a clear and systematic framework is needed in compiling a literature review-based research flow. The goal is that readers or other researchers who want to read this paper can easily find the information they are looking for from each point being reviewed. Hence, we decide to use the systematic literature review (SLR) method for literature review research, which has never been used by previous researchers in the field of detection of Plasmodium parasites. Furthermore, to provide a better understanding of the reviewed topic, we present a visual representation of four types of Plasmodium parasite species and their life cycles as shown in Table. 1.

Table 1 The four species of Plasmodium parasites and their life stages

\begin{tabular}{|c|c|c|c|c|}
\hline \multirow{2}{*}{ Life stage } & \multicolumn{4}{|c|}{ Species } \\
\hline & P. Falciparum & P. Vivax & P. Malariae & P. Ovale \\
\hline Trophozoite & & & & \\
\hline Schizont & & & & \\
\hline Gametocyte & & & & \\
\hline
\end{tabular}




\section{Methodology}

\subsection{Systematic literature review (SLR)}

Today, the review method that employs a systematic literature review has become a stable review standard [14]. The SLR is defined as a series of activities assessing, interpreting, and identifying all existing research facts and aims to answer predetermined research questions [15]. The SLR method is developed systematically and follows the stages and protocols that can minimize the occurrence of bias and subjective understanding [16]. Several systematic literature review studies have been carried out in various fields. For example, Prastyo [17] conducted a review of the development of paperless applications in Indonesia. The aim was to investigate with more details paperless applications in the form of its usage, platform, impact, and challenges for Indonesia. Then, Wahono [14] conducted a review of software defect predictions. The research aimed at identifying and analyzing research trends, methods, datasets, and frameworks.

The systematic literature review is carried out with three stages as shown in Fig. 1, starting from planning, implementing, and reporting the results of the review. In this paper, the initial stage is to identify the need for a systematic review of the detection of the Plasmodium parasite. After that, a review protocol is developed to maintain the focus of the review and reduce the possibility of researcher bias. At this stage, several processes are carefully performed, such as formulating research questions, compiling search strategies, carrying out the process of selecting literature data based on predetermined criteria (inclusion and exclusion), assessing the quality of each literature, conducting data extraction, and finally synthesizing the results.

Several considerations should be taken into account before conducting a systematic literature review covering the formulation of search keywords, a compilation of research questions, and synthesizing data. This section would determine the quality of the answers to a research question and the key results of the present literature review. Also, the research question should be made according to PICOC (population, intervention, comparison, outcomes, and context). A population is a field group of a research area. Meanwhile, the intervention is the detailed aspect of the research, and the comparison is parts of the research that will be compared with the intervention. The outcomes refer to the results of an intervention (I), and the context is a field coverage of the research. Review protocols are explained at the discussion points 3.2, 3.3, 3.4, and 3.5.

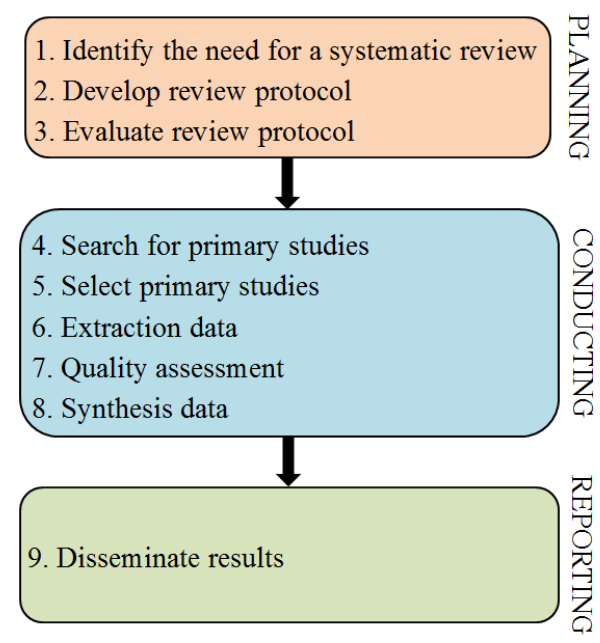

Fig. 1 Systematic literature review steps

\subsection{Research questions}

The formulation of research questions (RQ) is used to maintain the focus in the implementation of the review [17]. They aim to guide the process of searching and extracting literature. The formulation of research questions can be arranged based on five elements, which are known as PICOC (population, intervention, comparison, outcomes, and context). Population refers to 
the targeted group of the research. Intervention is a detailed aspect of the research or issues that attract researchers. Comparison is defined as the aspect of the research where the intervention (I) will be compared. Outcomes are the results of the intervention (I), and Context is the environment of the research [16]. Table 2 illustrates the PICOC structure of the research question used in this paper.

Table 2 PICOC summary

\begin{tabular}{|c|c|}
\hline Population & Automatic detection, detection system, object detection \\
\hline Intervention & Parasites, plasmodium, malaria, blood smears, thick blood, thin blood, data sets, methods \\
\hline Comparison & n/a \\
\hline Outcomes & The accuracy of the detection of plasmodium, the performance of the method used \\
\hline Context & Medical and academic studies \\
\hline
\end{tabular}

The questions and motivations of this study were made based on the PICOC formulation above and according to the needs of the topics chosen. The list of research questions is shown in Table 3.

Table 3 Research question (RQ)

\begin{tabular}{|c|c|c|}
\hline ID & Question & Motivation \\
\hline RQ1 & $\begin{array}{l}\text { What is the annual number of Plasmodium parasitic } \\
\text { detection studies? }\end{array}$ & $\begin{array}{l}\text { Identify the number of studies each year related to the } \\
\text { detection of Plasmodium parasites }\end{array}$ \\
\hline RQ2 & $\begin{array}{l}\text { What categories of publications are mostly in the research on } \\
\text { the detection of Plasmodium parasites? }\end{array}$ & $\begin{array}{c}\text { Identify the category of the most types of publications } \\
\text { in the research on the detection of Plasmodium } \\
\text { parasites }\end{array}$ \\
\hline RQ3 & $\begin{array}{l}\text { What kinds of contributions did the authors make of the } \\
\text { Plasmodium parasite detection research? }\end{array}$ & $\begin{array}{l}\text { Identify the type of the contribution the author } \\
\text { provided from the research }\end{array}$ \\
\hline RQ4 & $\begin{array}{l}\text { What types of datasets are used for the automatic detection } \\
\text { of Plasmodium parasites? }\end{array}$ & Identify the types of datasets used in the research \\
\hline RQ5 & What methods are used to detect Plasmodium parasites? & $\begin{array}{l}\text { Identify the type of methods used to detect } \\
\text { Plasmodium parasites }\end{array}$ \\
\hline RQ6 & $\begin{array}{l}\text { What method is most widely used to detect Plasmodium } \\
\text { parasites? }\end{array}$ & Identify the most used method \\
\hline RQ7 & $\begin{array}{l}\text { What method has the best performance for the detection of } \\
\text { Plasmodium parasites? }\end{array}$ & Identify the best performance of the used methods \\
\hline
\end{tabular}

The research questions (RQ1-RQ2) are the aspects of assessment aiming to identify the trends from studies related to the automatic detection of Plasmodium parasites. The research questions (RQ3-RQ7) are used to identify several aspects, namely the type of dataset used, the proposed method, the performance of the method, the most widely used method, and the contribution of each study.

\subsection{Search strategy}

The search strategy aims to compile the literature used in this paper. The search stage generates literature data from relevant sources and then selects appropriate keywords according to the summary PICOC to answer research questions (RQ). For that reason, the preparation of the search strategy involves a summary of PICOC and research questions (RQ) to find the right keywords. Here are the keyword preparation steps:

(1) Identify the search terms from PICOC (Population and Intervention).

(2) Identify the search terms from research questions.

(3) Identify the alternative spellings, antonyms, and synonyms of the search term.

(4) Performs the search word construction by using boolean operations (AND, OR).

Thus, the paper obtains the following keywords:

(automatic) AND (Plasmodium OR parasites) AND (malaria) AND (detection) AND (thick blood OR blood smear) AND (thin blood OR blood smear). 
The possible use of keywords in each database would be different, depending on the relevance and requirements of each database. To meet the specific requirements of each database, it is necessary to adjust the search terms in order to get the relevant data. This review only inlvolved papers that were open access. The search was given a limit in the forms of publication year i.e. between 2010 and 2019 and categories which fell into journals and conference proceedings. Next, the database used in the search is presented as follows:

(1) IEEE eXplore

(2) ScienceDirect

(3) SpringerLink

(4) AIP Publishing

(5) Nature

\subsection{Data selection}

This stage aims to select data (journal articles) and decide whether they are suitable for use in SLR research or not. The inclusion means that the criteria for journal articles that are worthy of being selected while the exclusions refer to the criteria for journal articles that are not suitable for selection. The inclusion and exclusion criteria are shown in Table 4.

Table 4 The inclusion and exclusion criteria

\begin{tabular}{|c|c|}
\hline \multirow{3}{*}{$\begin{array}{c}\text { The inclusion } \\
\text { criteria }\end{array}$} & Journal articles should be published in the last ten years starting from 2010 to 2019 \\
\cline { 2 - 2 } & The journal article comes from one category of publication of journal papers or conference proceedings \\
\cline { 2 - 2 } & $\begin{array}{c}\text { The journal article describes how to collect data, the methods used, and the contributions made to the } \\
\text { literature }\end{array}$ \\
\hline $\begin{array}{c}\text { The exclusion } \\
\text { criteria }\end{array}$ & Journal articles are not written in English \\
\cline { 2 - 2 } & Research results have no strong validation or do not include experimental results \\
\hline
\end{tabular}

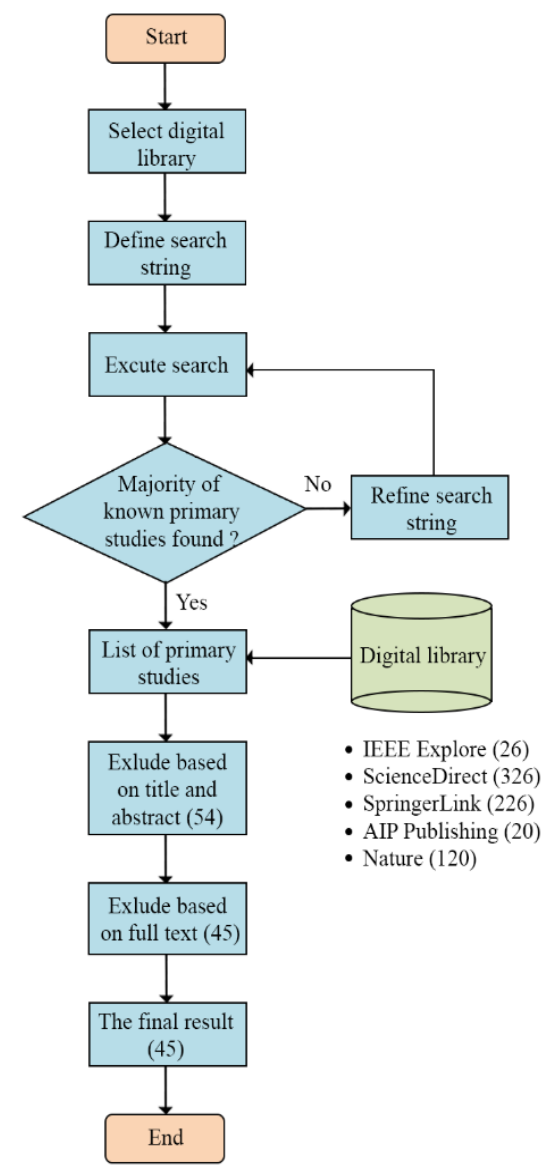

Fig. 2 Data search and selection 
After the search is performed, the data is obtained and stored in a computer software, which is called Mendeley, functions to store and manage the search results. The search process is carried out carefully by defining appropriate search terms for each database to produce the amount of data that is identified in each phase, such as shown in Fig. 2. The data selection process meeting the inclusion and exclusion criteria is carried out in two stages of exclusion, based on the title and abstract, as well as an exception based on the full text.

This first stage yields in fifty-four kinds of literature. The exceptions were then made based on the full text of the fifty-four existing literature. Another aspect that needs to be considered other than the inclusion and exclusion is regarding its relevanancy with the desired objectives from the research questions. Furthermore, the selected data are extracted from the body of literature to produce the primary data. This process will be explained in detail in the next sub discussion.

\subsection{Data extraction}

To produce the primary data that could answer research questions, the selected information is performed for data extraction. To facilitate the data extraction process, it takes several properties to compile the data extraction form. This property is identified through research questions and then analyzed. It was decided to be loaded in Microsoft Excel software to facilitate the mapping process. The following properties that were used to answer research questions are shown in Table 5 .

Table 5 Mapping of data extraction properties for RQ

\begin{tabular}{|c|c|}
\hline Properties & Research Question (RQ) \\
\hline Year, author, title, type, publication & RQ1, RQ2 \\
\hline Datasets & RQ4 \\
\hline Method & RQ5, RQ6, RQ7 \\
\hline Performance & RQ7 \\
\hline Contribution & RQ3 \\
\hline
\end{tabular}

\subsection{Quality assessment}

To ascertain whether or not the literature data follows the criteria, the data is based on the following criteria (inclusion and exclusion):

(1) Are the selected journal articles edited in between 2010 and 2019 ?

(2) Are the journal articles derived from one type of publication, i.e. journal papers or conference proceedings?

(3) Does the journal article explain the data collection methods used in the research?

(4) Does the journal article explain the method used to detect Plasmodium parasites?

(5) Do the journal articles explain the contributions made in research?

\subsection{Data synthesis}

Data synthesis aims to analyze the information from data that has been obtained previously through the extraction process. At this stage, all data will then be analyzed to obtain concrete evidence and provide answers to research questions (RQ). The data are analyzed using the following guidelines:

(1) What is the annual number of Plasmodium parasitic detection studies? (RQ1).

(2) What categories of publications are mostly in the research on the detection of Plasmodium parasites? (RQ2).

(3) What kinds of contributions do the authors make of the Plasmodium parasite detection research? (RQ3).

(4) What types of datasets are used for the automatic detection of Plasmodium parasites? (RQ4).

(5) What methods are used to detect Plasmodium parasites? (RQ5).

(6) What method is most widely used to detect Plasmodium parasites? (RQ6).

(7) What method has the best performance for the detection of Plasmodium parasites? (RQ7). 


\section{Results and Discussion}

\subsection{Research trends}

This review collects forty-five pieces of literature that developed an automatic detection system for Plasmodium parasites. The body of literature is collected through a selection process according to the inclusion and exclusion criteria and the purpose of the research questions. The collected literature is then grouped according to the year of publication to see research trends related to the detection of automatic Plasmodium parasites. It will provide answers to the research questions (RQ1). The distribution of publications from year to year can be seen in Fig. 3.

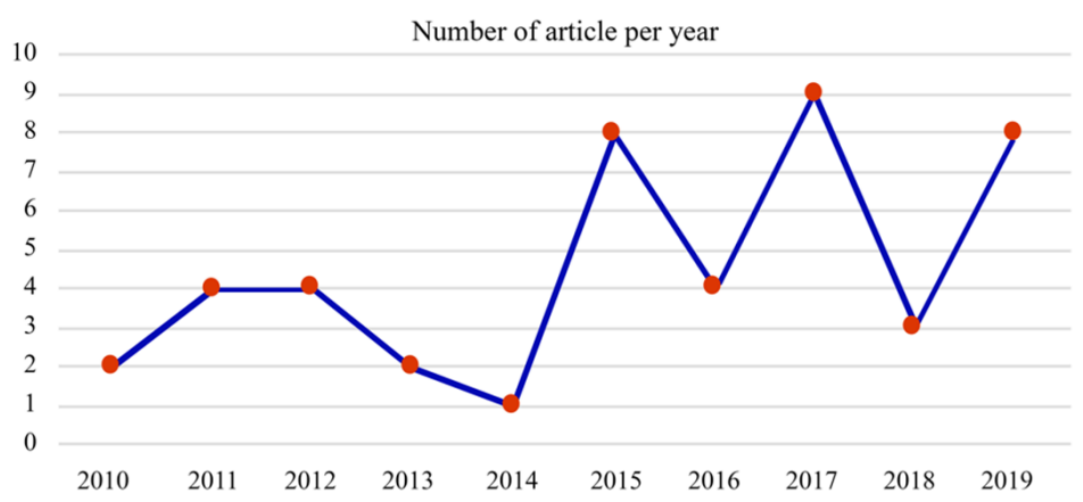

Fig. 3 The research trend of the automatic detection of Plasmodium annually

\subsection{Publication type category}

Forty-five articles are collected and identified according to the type of publication. This aims to provide the answers to research questions (RQ2). The types of publications are divided into two, namely journal articles and conference proceedings. The present research found that the quantity of journal article publications is slightly larger than conferences/proceedings. The distribution of types of publications is shown in Fig. 4.

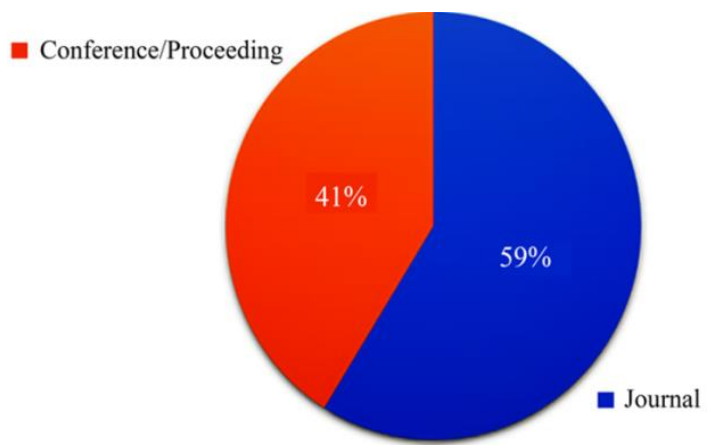

Fig. 4 The distribution of publication types

Twenty articles collected over the past ten years yield 59\% of journal articles and $41 \%$ of conference articles/proceedings. To find out the distribution of the number of articles in each journal and conference/proceedings, we classified each article according to the types of the publication. For more details, Fig. 5 displays some selected journals and the distribution of the number of articles in each journal. Four journals with the highest number of articles includes Multimedia Tools and Applications (two articles), Journal of Medical Systems (two articles), Scientific Reports (three articles), and Malaria Journal (four articles).

Fig. 6 shows the distribution of conference/proceedings and the number of articles in each conference selected in this research. Most of the articles published in the conference are about the same number. Only three conferences producemore than one paper, covering EMBS (two articles), KST (two articles), and AIP conference (three sections). 


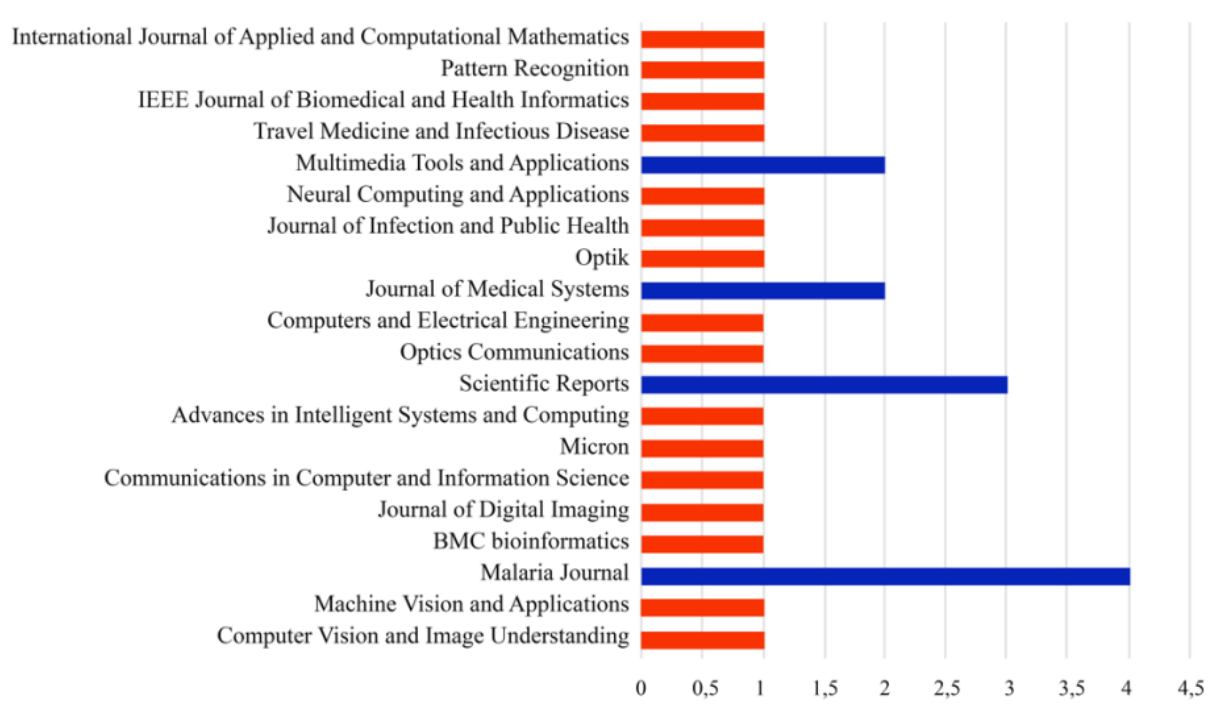

Fig. 5 The distribution of selected journal publication

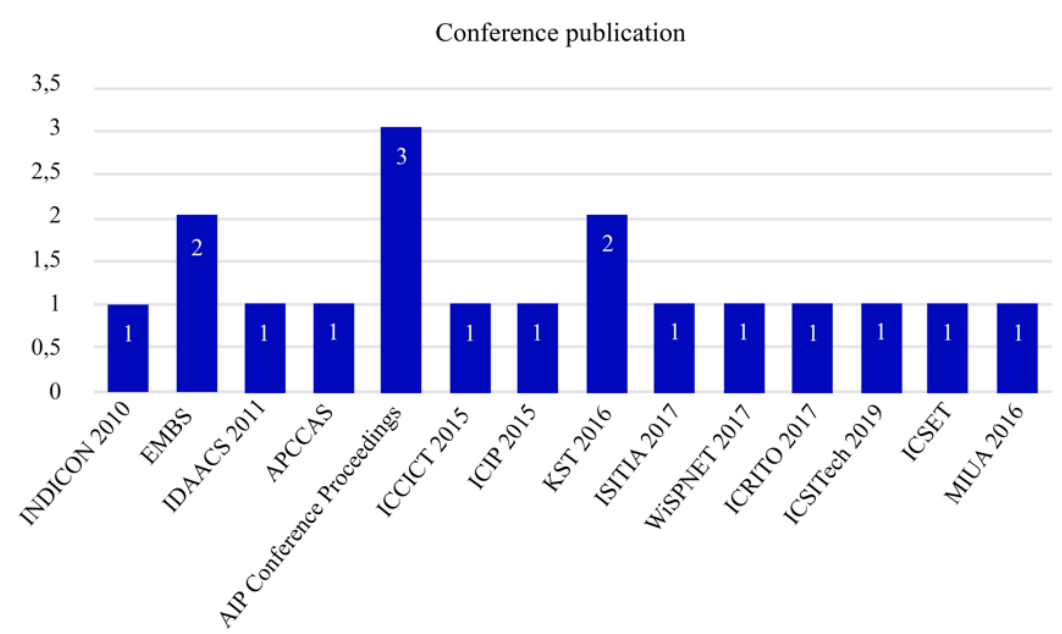

Fig. 6 The distribution of selected conference proceeding

\subsection{Research contribution}

The research contributions are identified according to how the objectives of each research are achieved. This section attempts to elaborate on the answers to the research questions (RQ3). Several categories are employed to extract the contribution information from each literature, namely detection, segmentation, and classification. In each literature, the authors claim that the results of the proposed method work well. Hence, in this research, the pieces of literature need to be appropriately identified to validate their findings. It should be noted that, in this paper, the intended contribution focused on evaluating the approach and proposed method used to solve the research problem. The reason is that seeing the distribution of existing methods from the literature does not use a stand-alone method. In other words, most of the proposed methods use a combination or modification of existing methods.

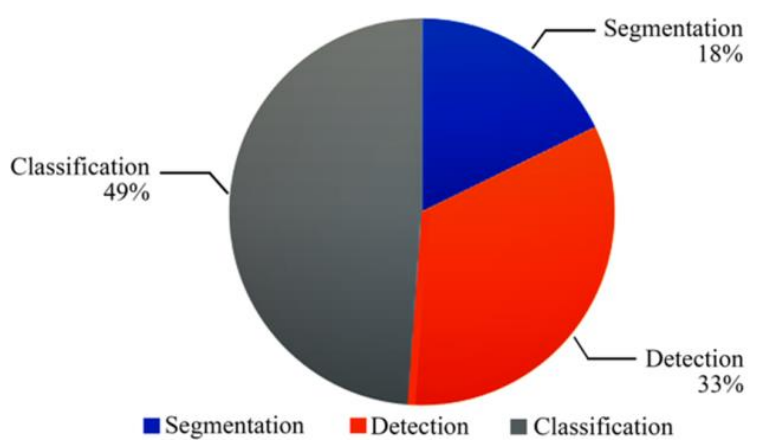

Fig. 7 The percentage contribution of research methods 
Therefore, we limit the scope of the assessment of contributions according to the three categories mentioned above by using the reference method from each literature. The main result discovers that $49 \%$ of the research included in this paper is linked to the classification method, and $33 \%$ of them are related to the detection method. Further, $18 \%$ of the research literature is related to the segmentation method, as shown in Fig. 7. The full list of contribution assessment results is shown in Table 6.

Table 6 The list of selected papers of automatic detection of Plasmodium parasites

\begin{tabular}{|c|c|c|c|c|c|}
\hline ID & Primary Author & Topics & Method/Contribution & Datasets & Performance \\
\hline 1 & $\begin{array}{c}\text { Subhamoy } \\
\text { Mandal (2010) }\end{array}$ & Segmentation & Normalized Cut Algorithm (N-Cut) & Public & $\begin{array}{c}\text { Rand Index (RI) HSV } \\
\text { color }=80-95 \%\end{array}$ \\
\hline 2 & $\begin{array}{l}\text { F. Boray Tek } \\
\qquad(2010)\end{array}$ & Classification & $\begin{array}{l}\text { K-Nearest Neighbors (KNN) classifier } \\
\text { based on distance RL1 }\end{array}$ & Private & $\begin{array}{c}\text { Sensitivity }=72.4 \%, \text { PPV }= \\
85.8 \%, \mathrm{NPV}=94.6 \% \\
\text { Specificity }=97.6 \%, \text { Overall } \\
\text { Accuracy }=93.3 \%\end{array}$ \\
\hline 3 & $\begin{array}{l}\text { Matthias Elter } \\
\text { (2011) }\end{array}$ & Classification & Support Vector Machine (SVM) & Private & $\begin{array}{c}\text { Sensitivity }=97 \% \\
\text { false-positive detections }=0.8 \%\end{array}$ \\
\hline 4 & $\begin{array}{c}\text { S. } \\
\text { Kaewkamnerd } \\
(2011)\end{array}$ & Classification & $\begin{array}{l}\text { Pre-processing, segmentation, feature } \\
\text { extraction, classification }\end{array}$ & Private & $\begin{array}{l}\text { Correctly Performed with a } \\
\text { Success } 60 \%\end{array}$ \\
\hline 5 & $\begin{array}{c}\text { S.K } \\
\text { Kumarasamy } \\
(2011) \\
\end{array}$ & Classification & $\begin{array}{c}\text { A rule-based algorithm \& Support } \\
\text { Vector Machine (SVM) }\end{array}$ & Private & $\begin{array}{c}\text { Accuracy }=97 \% \text { for cell } \\
\text { segmentation, Accuracy }=86 \% \\
\text { parasite detection }\end{array}$ \\
\hline 6 & $\begin{array}{c}\text { Yashasvi } \\
\text { Purwar (2011) }\end{array}$ & Classification & $\begin{array}{l}\text { Probabilistic K-Means Clustering } \\
\text { (PKMC) }\end{array}$ & Private & $\begin{aligned} \text { Sensitivity } & =100 \%, \text { Specificity } \\
& =50-88 \%\end{aligned}$ \\
\hline 7 & $\begin{array}{l}\text { S.Kareem } \\
(2012)\end{array}$ & Classification & $\begin{array}{l}\text { Modified annular ring ratio (ARR) } \\
\text { based on the relative size of the } \\
\text { parasitic nucleus and based on the } \\
\text { threshold concerning pixel intensity }\end{array}$ & Private & $\begin{array}{l}\text { Accuracy }=87 \% \\
\text { Sensitivity }=90 \%\end{array}$ \\
\hline 8 & $\begin{array}{l}\text { S. } \\
\text { Kaewkamnerd } \\
(2012)\end{array}$ & Classification & $\begin{array}{l}\text { Image acquisition, pre-processing, } \\
\text { image segmentation, feature extraction } \\
\text { and classification }\end{array}$ & Private & $\begin{array}{c}\text { Parasite-positive }=95 \%, \\
\text { Parasite-negative }=68,5 \%, \mathrm{P} . \\
\text { vivax parasite }=75 \%, \mathrm{P} . \\
\text { falciparum }=90 \%\end{array}$ \\
\hline 9 & $\begin{array}{c}\text { Keerthana } \\
\text { Prasad (2012) }\end{array}$ & Classification & $\begin{array}{c}\text { Segmentation, feature extraction, } \\
\text { classification }\end{array}$ & Private & $\begin{array}{c}\text { Accuracy }=96 \%, \text { False } \\
\text { positive }=20 \%\end{array}$ \\
\hline 10 & $\begin{array}{l}\text { J. Somasekar } \\
\text { (2012) }\end{array}$ & Detection & $\begin{array}{l}\text { Grayscale conversion, Median } \\
\text { Filtering, Extraction of parasite } \\
\text { components, a complement of the } \\
\text { extracted image, Morphological } \\
\text { operation, Highlighting the concerned } \\
\text { parasite }\end{array}$ & Public & $\begin{array}{l}\text { Sensitivity }=94.87 \%, \\
\text { Specificity }=97.3 \%\end{array}$ \\
\hline 11 & $\begin{array}{l}\text { Dev Kumar Das } \\
\text { (2013) }\end{array}$ & Classification & $\begin{array}{l}\text { Bayesian learning and support vector } \\
\text { machine (SVM) }\end{array}$ & Private & $\begin{array}{c}\text { Bayesian: } 84 \% \text { filtering } \\
\text { accuracy, } 98.10 \% \text { sensitivity } \\
\text { and } 68.91 \% \text { specificity. SVM: } \\
\text { filtering accuracy } 83.5 \%, \\
\text { sensitivity } 96.62 \% \text { specificity } \\
88.51 \%,\end{array}$ \\
\hline 12 & $\begin{array}{c}\text { Feminna } \\
\text { Sheeba (2013) }\end{array}$ & Detection & $\begin{array}{c}\text { Image Acquisition, Image Adjusting, } \\
\text { Segmentation, Detection of Infected } \\
\text { RBCs, Detection of Gametocytes } \\
\text { Segmentation }\end{array}$ & Private & $\begin{array}{l}\text { Sensitivity }=75 \% \\
\text { Specificity }=78 \%\end{array}$ \\
\hline 13 & $\begin{array}{l}\text { D.L Omucheni } \\
(2014)\end{array}$ & Segmentation & Principal Component Analysis (PCA) & Private & $\begin{array}{l}\text { 590-700 spectral range } \\
\text { identified }\end{array}$ \\
\hline 14 & $\begin{array}{c}\text { A.S } \\
\text { Abdul-Nasir } \\
(2015) \\
\end{array}$ & Segmentation & $\begin{array}{l}\text { Cascaded moving k-means (MKM) } \\
\text { and fuzzy c-means (FCM) }\end{array}$ & Private & $\begin{array}{c}\text { Sensitivity }=78.23 \% \\
\text { Specificity }=99.48 \% \\
\text { Accuracy }=98.80 \%\end{array}$ \\
\hline 15 & $\begin{array}{l}\text { S.S.Savkare } \\
\quad(2015)\end{array}$ & Classification & Support Vector Machine (SVM) & Private & $\begin{array}{c}\text { Correct detection }=98.66 \% \\
\text { Sensitivity }=98.94 \% \\
\text { Specificity }=96.12 \%\end{array}$ \\
\hline 16 & $\begin{array}{l}\text { Manas Kotepui } \\
\text { (2015) }\end{array}$ & Detection & Binary logistic regression & Private & $\begin{aligned} \text { Sensitivity } & =81.2 \%, \text { Specificity } \\
& =80.3 \%\end{aligned}$ \\
\hline 17 & $\begin{array}{l}\text { Yitian Zhao } \\
\text { (2015) }\end{array}$ & Classification & AdaBoost Classifier & Private & $\begin{array}{c}\text { Sensitivity }=74.7 \%, \\
\text { Specificity }=73.5 \%, \\
\text { Accuracy }=74.1 \% \text { AUC }=74.2 \%\end{array}$ \\
\hline 18 & $\begin{array}{l}\text { David Mas } \\
\quad(2015)\end{array}$ & Detection & Voxel Algorithm & Private & $\begin{array}{c}\text { Infected cells probability }= \\
93 \%, \text { Healthy cells probability } \\
=85 \%\end{array}$ \\
\hline
\end{tabular}


Table 6 The list of selected papers of automatic detection of Plasmodium parasites (continued)

\begin{tabular}{|c|c|c|c|c|c|}
\hline ID & Primary Author & Topics & Method/Contribution & Datasets & Performance \\
\hline 19 & $\begin{array}{l}\text { J. Somasekar } \\
\text { (2015) }\end{array}$ & Segmentation & $\begin{array}{l}\text { Fuzzy C-means }(\mathrm{FCM})+\text { Minimum } \\
\text { Perimeter Polygon }(\mathrm{MPP}) \text { method }\end{array}$ & Private & $\begin{array}{c}\text { Sensitivity }=98 \%, \text { Specificity }= \\
93.3 \%, \mathrm{PPV}=98.65 \% \\
\mathrm{NPV}=90.33 \%\end{array}$ \\
\hline 20 & $\begin{array}{l}\text { Meng-Hsiun } \\
\text { Tsai (2015) }\end{array}$ & Segmentation & MPIE method & Private & $\begin{array}{l}\text { Sensitivity }=98.09 \%, \text { PPV }= \\
68.33 \%, \text { F-measure }=80.55 \%\end{array}$ \\
\hline 21 & $\begin{array}{l}\text { S.S.Savkare } \\
\quad(2015)\end{array}$ & Segmentation & K-Mean Clustering \& global threshold & Private & $\begin{array}{l}\text { The accuracy of the overall } \\
\text { segmentation algorithm is } \\
95.5 \%\end{array}$ \\
\hline 22 & $\begin{array}{l}\text { W. Preedanan } \\
\text { (2016) }\end{array}$ & Classification & Support Vector Machine (SVM) & Private & $\begin{array}{c}\text { Sensitivity }=92,71 \%, \\
\text { Specificity }=97,35 \%, \\
\text { Accuracy }=97,17 \%\end{array}$ \\
\hline 23 & $\begin{array}{l}\text { Pargorn } \\
\text { Puttapirat } \\
\text { (2016) }\end{array}$ & Segmentation & $\begin{array}{c}\text { Image Enhancement, Background } \\
\text { subtraction, Morphological process, } \\
\text { Separation of touching and overlapped } \\
\text { region, Labeling }\end{array}$ & Private & $\begin{array}{l}\text { Our processing framework } \\
\text { provides } 97 \% \text { accuracy }\end{array}$ \\
\hline 24 & $\begin{array}{l}\text { Zheng Zhang } \\
\quad(2016)\end{array}$ & Classification & $\begin{array}{c}\text { Multi-class Support Vector Machines } \\
\text { (SVM) and Viola-Jones Object } \\
\text { Detection Framework }\end{array}$ & Private & $\begin{array}{l}\text { Results } 50 \% \text { and cell detection } \\
\text { algorithm that applied the } \\
\text { Hough transformation was } 24 \%\end{array}$ \\
\hline 25 & $\begin{array}{l}\text { Lu' is Rosado } \\
\text { (2016) }\end{array}$ & Classification & Support Vector Machine (SVM) & Private & $\begin{array}{c}\text { Trophozoite detection } \\
\text { sensitivity }=80.5 \% \\
\text { specificity }=93.8 \%, \text { white blood } \\
\text { cells sensitivity }=98.2 \% \\
\text { specificity }=72.1 \%\end{array}$ \\
\hline 26 & $\begin{array}{l}\text { Budi Sunarko } \\
\quad(2017)\end{array}$ & Classification & Linear Discriminant Analysis (LDA) & Private & $\begin{array}{l}\text { The correlation between } \\
\text { algorithm achievement and the } \\
\text { expert reader is } r=0.836\end{array}$ \\
\hline 27 & $\begin{array}{c}\text { A.S. } \\
\text { Abdul-Nasir } \\
(2017) \\
\end{array}$ & Segmentation & Enhanced K-Means (EKM) clustering & Private & $\begin{array}{l}\text { Accuracy }=99.20 \% \\
\text { Sensitivity }=87.53 \% \\
\text { Specificity }=99.58 \%\end{array}$ \\
\hline 28 & $\begin{array}{l}\text { H.A Nugroho } \\
\text { (2017) }\end{array}$ & Detection & $\begin{array}{l}\text { Otsu thresholding method, } \\
\text { morphological operation and large } \\
\text { binary object (BLOB) analysis }\end{array}$ & Private & $\begin{array}{l}\text { Sensitivity }=87.5 \%, \text { PPV } \\
\text { parameters }=75.7 \%\end{array}$ \\
\hline 29 & $\begin{array}{l}\text { Vinayak Joshi } \\
\quad(2017)\end{array}$ & Detection & $\begin{array}{l}\text { Vision Quest's + k-Nearest Neighbors } \\
(\text { KNN) + Partial Least Square (PLS) }\end{array}$ & Private & $\begin{array}{c}\text { Sensitivity }=95 \% \\
\text { Specificity }=100 \% \text { for overall } \\
\text { MR detection, Sensitivity }=65 \% \\
\text { Specificity }=94 \% \text { for retinal } \\
\text { bleaching, Sensitivity }=62 \% \\
\text { Specificity }=100 \% \text { for vessel } \\
\text { discoloration, } \\
\text { Sensitivity }=73 \% \\
\text { Specificity }=96 \% \text { for bleeding }\end{array}$ \\
\hline 30 & $\begin{array}{l}\text { S. Sankarana } \\
\text { (2017) }\end{array}$ & Detection & $\begin{array}{l}\text { Six-Sigma } \\
\text { threshold and modified Hough } \\
\text { Transform technique (CBDHT) }\end{array}$ & Private & $\begin{array}{c}\text { Precision }=96 \%, \text { Recall }=97 \% \\
\text { and F-Measure }=97 \%\end{array}$ \\
\hline 31 & $\begin{array}{l}\text { Riddhi } \\
\text { Hathiwalaa } \\
\text { (2017) }\end{array}$ & Detection & $\begin{array}{l}\text { Embedded System Light microscopy } \\
\text { (LM), Light Emission Diode } \\
\text { fluorescence microscopy (LED FM), } \\
\text { rapid diagnostic tests (RDT) }\end{array}$ & Private & $\begin{array}{c}\text { Sensitivity and specificity } \\
71.2 \% \text { and } 96.3 \% \text { respectively } \\
\text { for FM LEDs and } 91 \% \text { and } \\
96.8 \% \text { for RDTs }\end{array}$ \\
\hline 32 & $\begin{array}{l}\text { Maitreya Maity } \\
\quad(2017)\end{array}$ & Classification & $\begin{array}{l}\text { Naïve Bayes, C4.5 Decision tree, } \\
\text { Instance-Based Learning (IB1) }\end{array}$ & Private & $\begin{array}{l}\text { Sensitivity }=99.2 \% \\
\text { Specificity }=99.6 \%\end{array}$ \\
\hline 33 & $\begin{array}{c}\text { Ishan R } \\
\text { (2017) }\end{array}$ & Classification & Support Vector Machine (SVM) & Private & $\begin{array}{l}\text { Sensitivity }=86,34 \%, \\
\text { Specificity }=96,60 \%\end{array}$ \\
\hline 34 & $\begin{array}{l}\text { Shipra Saraswat } \\
\text { (2017) }\end{array}$ & Detection & $\begin{array}{l}\text { Image acquisition, Pre-processing, } \\
\text { Conversion in HUE \& value image, } \\
\text { extraction of blue pixel values, } \\
\text { Enhanced images, parasites extracted }\end{array}$ & Public & $\begin{array}{c}\text { Sensitivity }=98.5 \%, \\
\text { Specificity }=75 \%, \\
\text { Accuracy }=95 \%, \text { PPV }=95.7 \%\end{array}$ \\
\hline 35 & $\begin{array}{l}\text { Naveed Abbas } \\
\quad(2018)\end{array}$ & Classification & $\begin{array}{l}\text { Algorithm of Gaussian Mixture Model } \\
\text { (GMM) }\end{array}$ & Public & $\begin{array}{l}\text { Sensitivity }=98 \% \\
\text { Specificity }=97 \%\end{array}$ \\
\hline 36 & $\begin{array}{l}\text { S. Shuleenda } \\
\text { Devi (2018) }\end{array}$ & Classification & $\begin{array}{l}\text { Hybrid classification Support Vector } \\
\text { Machine (SVM), k-Nearest Neighbors } \\
\text { (KNN) and Naïve Bayes }\end{array}$ & Private & $\begin{array}{c}\text { Sensitivity }=95.86 \%, \\
\text { Accuracy }=98.5 \%, \text { F-score }= \\
93.82 \%\end{array}$ \\
\hline 37 & $\begin{array}{c}\text { Hagen } \\
\text { Frickmanna } \\
(2018)\end{array}$ & Detection & $\begin{array}{l}\text { Embedded System Meridian } \\
\text { illumigene Malaria platform }\end{array}$ & Private & $\begin{array}{c}\text { Sensitivity }=98.7 \%, \\
\text { Specificity }=99.6 \%, \\
\text { PPV }=98.7 \%, \mathrm{NPV}=99.6 \%\end{array}$ \\
\hline
\end{tabular}


Table 6 The list of selected papers of automatic detection of Plasmodium parasites (continued)

\begin{tabular}{|c|c|c|c|c|c|}
\hline ID & Primary Author & Topics & Method/Contribution & Datasets & Performance \\
\hline 38 & $\begin{array}{c}\text { A.Revan } \\
\text { Prananda (2019) }\end{array}$ & Detection & $\begin{array}{l}\text { Normalization, Segmentation, } \\
\text { Detection (BLOB analysis), False } \\
\text { Positive Reduction (Feature } \\
\text { Extraction, GLCM and GLRLM), } \\
\text { Support Vector Machine (SVM) }\end{array}$ & Private & $\begin{array}{c}\text { Accuracy }=97.4 \%, \text { Sensitivity= } \\
100 \%, \text { Specificity }=94.8 \% \\
\text { PPV }=95.1 \%, \text { NPV }=100 \%\end{array}$ \\
\hline 39 & $\begin{array}{l}\text { H.A Nugroho } \\
\qquad(2019)\end{array}$ & Detection & $\begin{array}{l}\text { Convolutional Neural Network (CNN) } \\
\text { and Transfer Learning }\end{array}$ & Private & $\begin{array}{c}\text { Transfer learning: } \\
\text { PPV=98.46\% Sensitivity = } \\
97.00 \%, \text { CNN: Sensitivity = } \\
97.00 \%, \text { PPV }=75.29 \%\end{array}$ \\
\hline 40 & $\begin{array}{l}\text { Feng Yang } \\
\text { (2019) }\end{array}$ & Detection & Convolutional Neural Network (CNN) & Private & $\begin{array}{c}\text { Accuracy }=93.46 \%, \text { AUC } \\
=98.39 \%, \text { Sensitivity }=92.59 \%, \\
\text { Specificity }=94.33 \%, \\
\text { Precision }=94.25 \%, \\
\text { NPV }=92.74 \%\end{array}$ \\
\hline 41 & $\begin{array}{c}\text { A. } \\
\text { Pages-Zamora } \\
(2019)\end{array}$ & Detection & $\begin{array}{l}\text { Expectation-Maximization (EM) } \\
\text { algorithm }\end{array}$ & Public & $\begin{array}{l}\text { Sensitivity MV decreases to the } \\
\text { range }[0,2 \%, 4,4 \%] \text {, except for } \\
\text { Fig. } 2 \text { to the range }[45 \%, 65 \%] \text {. } \\
\text { In contrast, DEM is able to } \\
\text { maintain higher sensitivity in } \\
\text { the range }[0.5 \%, 75 \%] \text { and up } \\
\text { to } 0.9 \% \text { for Fig. } 2 \text {. }\end{array}$ \\
\hline 42 & $\begin{array}{l}\text { E.P Mwanga } \\
\qquad(2019)\end{array}$ & Classification & $\begin{array}{l}\text { Midinfrared spectroscopy coupled } \\
\text { with supervised machine learning } \\
\text { (MIRML) }\end{array}$ & Private & $\begin{array}{c}\text { P. falciparum }=92 \% \text { overall } \\
\text { accuracy }(\text { specificity }=91.7 \% \\
\text { sensitivity }=92.8 \%) \text { and } \mathrm{P} . \\
\text { falciparum P. ovale } 85 \% \\
(\text { specificity }=85 \%, \text { sensitivity }= \\
85 \%)\end{array}$ \\
\hline 43 & $\begin{array}{l}\text { Purnima Pandit } \\
\text { (2019) }\end{array}$ & Classification & $\begin{array}{l}\text { Discrete Wavelet Coefficients (DWC) } \\
\text { \& Dynamic Time Warping Algorithm }\end{array}$ & Private & Result $=91,6 \%$ \\
\hline 44 & $\begin{array}{c}\text { Evashin Pillay } \\
(2019)\end{array}$ & Detection & $\begin{array}{c}\text { Embedded System Sysmex XN-30 } \\
\text { analyzer }\end{array}$ & Private & $\begin{array}{c}\text { Sensitivity }=100 \%, \text { Specificity }= \\
100 \%\end{array}$ \\
\hline 45 & $\begin{array}{l}\text { Vijayalakshmi } \\
\text { A (2019) }\end{array}$ & Classification & Transfer learning based VGG19-SVM & Private & Accuracy $=93,13 \%$ \\
\hline
\end{tabular}

\subsection{Dataset used for detection of Plasmodium parasite}

The datasets in forty-five literature are identified in this section. The datasets are divided into two categories, namely public and private datasets. The public dataset refers to the data that is publicly available or open access. In contrast, private datasets are the data obtained from a particular institution, laboratory, or hospital for use in research. The data are personal and are not used massively.

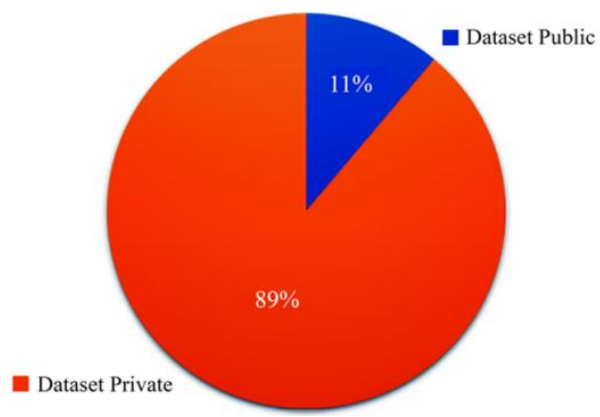

Fig. 8 Total distribution of datasets

This section explain the answers to the research questions (RQ4). As shown in Fig. 8, it is found that the use of private datasets is more dominant with a percentage of $89 \%$. It covers forty pieces of literature out of a total of forty-five existing pieces. Meanwhile, public datasets are only $11 \%$ or as much as five pieces of literature. Most private datasets are obtained from laboratories or hospitals while public datasets are mainly taken from DPDx-Malaria Image Library, Malariaspot, Centers for Disease Control and Prevention (CDC), and WebMicroscope. Table 6 illustrates the complete distribution of datasets usage from each literature. 


\subsection{Parasite Plasmodium detection method}

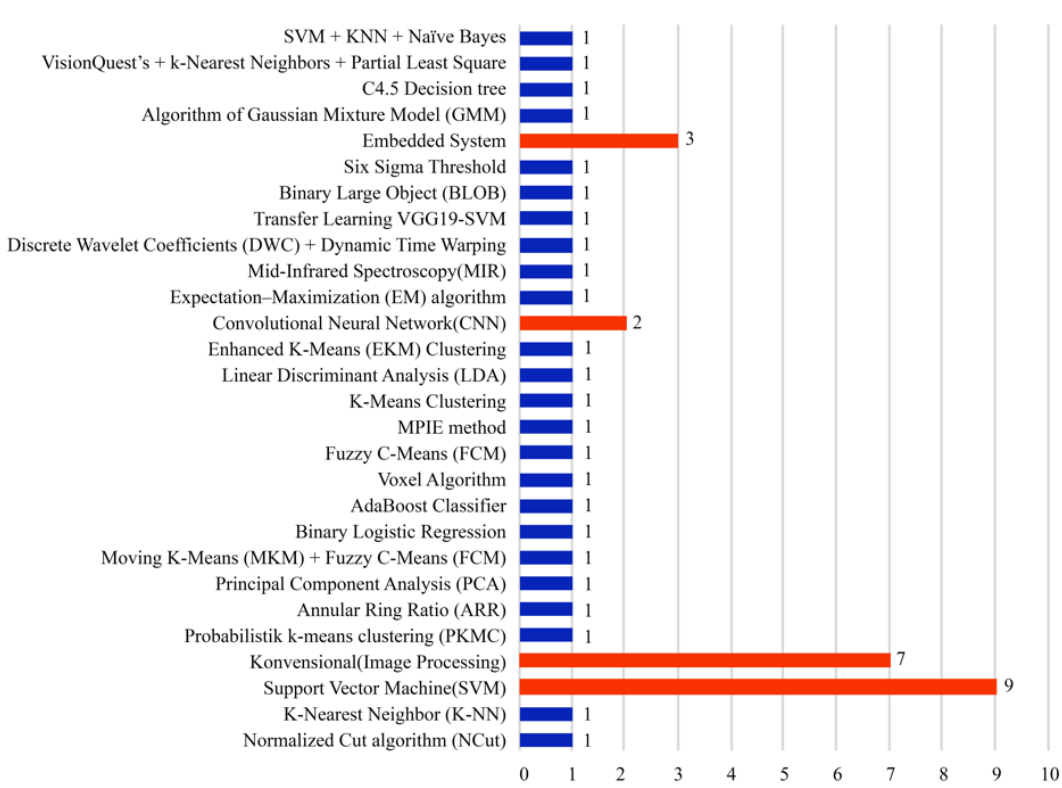

Fig. 9 The methods used in the detection of Plasmodium parasite

Method identification is carried out for forty-five selected pieces of literature. This section describes the answers to the research questions (RQ5). As many as twenty-eight methods are obtained, and most of the methods are not independent. It meant that most of them use a proposed combination method or modification of the method. Fig. 9 depicts that each literature proposes different methods and approaches to produce better performance in detecting Plasmodium parasites.

All methods in Fig. 9 are used by researchers in completing three main tasks in the field of Plasmodium parasites, namely detection, segmentation, and classification. The detection process is usually carried out by observing the region of interest (ROI) of a parasite in a blood smear image. After it successfully determining the ROI, the segmentation is then carried out by separating the parasite object from the background in the image. Therefore, further processing can be processed more easily and focus on certain segmented objects. Finally, the classification is implemented according to the number of classes in the case of each study. These three processes are actually interrelated with one another.

Several studies that developed the segmentation process include Haryanto [18] proposing color image segmentation in malaria parasites, which intends to accelerate the diagnosis process and achieve high malaria detection accuracy. Haryanto [18] segmented the species P.Valciparum with the Schizont life stage. Based on the experimental results, the proposed segmentation technique could improve the performance of the detection process of Plasmodium parasites.

Another research related to segmentation was carried out by Nugroho [19] which aimed to develop a Plasmodium segmentation scheme on thin blood smear images with different characteristics. There were three main stages in the research, namely pre-processing, grouping of image characteristics, and segmentation of Plasmodium. In the pre-processing stage, the saturation channel was extracted from the hue saturation value (HSV). Then, the image characteristics were classified based on the difference in standard deviation. After that, Otsu thresholding combined with morphological image processing was used to segment Plasmodium. The results of the performance evaluation reaches $97.99 \%, 82.23 \%$, and $99.33 \%$ for accuracy, sensitivity, and specificity respectively.

A similar study was conducted by Aladago [20] who proposed semantic segmentation of the life stage of the Plasmodium parasite to aid in an effective diagnosis. By using data augmentation and transfer learning, the proposed method reaches an accuracy of $85.86 \%$. The next important task after detection and segmentation is classification. In the research of Plasmodium parasites, the classification is needed to distinguish between infected and uninfected erythrocytes or to classify the types of Plasmodium species and their life stages. 
The research for classification tasks has also been implemented by several researchers including Pinkaew [21] who classified two types of parasites P. Valciparum and P.Vivax by using statistical features, such as mean, standard deviation, kurtosis, skewness, entropy, and four color channels. These features were then used for classification by using the support vector machine (SVM) method. The classification results reaches an accuracy of $85.71 \%$ and $78.72 \%$ for P. Valciparum and P.Vivax.

Another study related to classification was also carried out by Mohammed [22] by classifying one of the four types of Plasmodium species. In the early stages, the morphological processing system was used to extract red blood cells from the image of the blood smear. Then, red blood cells were grouped into infected and uninfected cells, and the number of red blood cells was counted on each image. Furthermore, Mohammed [22] used the Normalized Cross-Correlation (NCC) function to classify parasites. The results reaches $95 \%$ accuracy for detecting and counting red blood cells and $100 \%$ for detecting and classifying parasites into one of four types.

The most recent study related to classification was conducted by Kudisthalert [23] which consisted of two main parts, namely red blood cell count and classification of parasite life cycle stages. The calculation process was accomplished by a machine learning approach such as multi layer perceptron (MPL), linear discriminant analysis (LDA), and support vector machine (SVM). The experimental results show that the proposed method could count and classify correctly. The accuracy level reaches $97.94 \%$ and $98.12 \%$ for red blood cell count and classification, respectively. Based on Fig. 9 and some of the explanations above, the methods implemented in each study in the field of Plasmodium parasites varied widely. However, in general, the approaches proposed by researchers still adopt machine learning and deep learning algorithms and use image processing techniques or computer vision.

\subsection{Most used methods in the detection of Plasmodium}

Of the twenty-eight methods shown in Fig. 9, there are at least four of the most widely applied methods in automatic detection of Plasmodium parasites, including SVM, conventional image processing (CIP), embedded system (ES), and CNN. The methods are shown in Fig. 10.

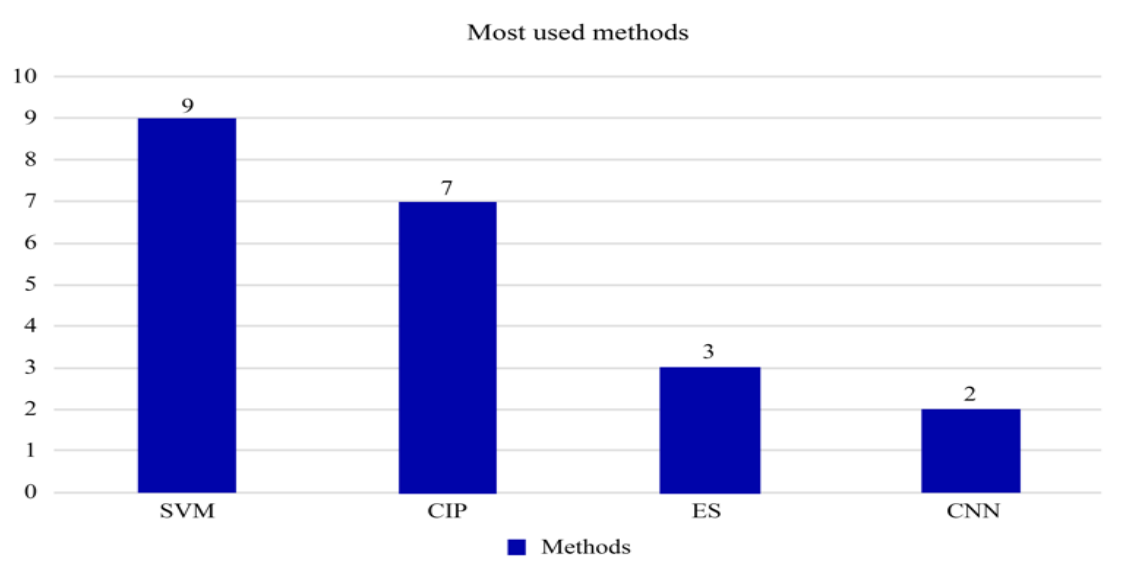

Fig. 10 Most used methods in the detection of Plasmodium parasite

This section explained the answers to the research question (RQ6). Fig. 10 shows that the machine learning method is still the primary choice of most researchers to assist them to solve research problems related to the detection of Plasmodium parasites. The support vector machine (SVM) is the only sufficient machine learning algorithm that is widely used in solving classification problems. If the whole of the twenty-eight methods illustrated in Fig. 9 is taken into consideration, as many as eleven of them are categorized machine learning methods that are used either independently or in combination with several other methods. This result indicates the reliability of machine learning methods or deep learning to identify Plasmodium parasites for segmentation, detection, or classification tasks by producing an accuracy rate above $90 \%$. 
Hence, it also affects the use of conventional methods that are slowly abandoned and switched to the development of machine learning and deep learning algorithms. However, these methods are not without weaknesses. For example, deep learning algorithms require much training data to produce significant levels of accuracy. In addition, long computational time also requires resources with a considerable enough power to run it. Therefore, there is a need for the development of optimization in computing and resources. In addition, another challenge that exists if we decide to use a machine learning or deep learning approach is the absence of a specific formulation for each case which will be solved by using this method. It means that the treatment of using machine learning and deep learning algorithms varies for each case or is experimental. It depends on the available resources such as the number of datasets, including the hardware specifications.

Furthermore, we identify the results from forty-five pieces of literature that have been collected. Nine of them use the SVM method. The use of the SVM method, especially in the field of detection of Plasmodium parasites, is mainly influenced by the characteristics of the dataset. Here, we describe the number of datasets used in the experiment with the SVM method.

The research conducted by Elter [24] used 256 images with the dimensions of $1000 \times 1000$ pixels. Das' study [25] used 150 images with species of (70 P. vivax, 40 P. falciparum, and 40 normal). Meanwhile, Savkare's study [26] used 68 images obtained by connecting a high-resolution digital camera to a microscope. Preedanan's study [27] collected 15 images with the dimensions of $1360 \times 1024$ pixels. Zhang's study [28] used 43 images, and Rosado's study [29] used 194 images. After that, Ishan's research [30] used a dataset of 87 images with the dimensions of $3136 \times 2352$ pixels, and Prananda's research [31] used 46 images.

Overall, the number of datasets used by researchers with the SVM method is no more than 300 images. It means that the SVM follows the characteristics of machine learning algorithms designed to handle small-scale datasets. Conversely, some researchers who apply deep learning algorithms such as CNN use more datasets according to the characteristics of deep learning algorithms designed to handle complex datasets. For example, Nugroho's [32] study used 330 images (148 plasmodia and 182 non-plasmodia), Yang's study [1] used 1819 images from 150 patients, and Vijayalakshmi's [33] study used 1030 infected and 1520 uninfected images.

\subsection{The method which performed best for the detection of Plasmodium}

This section explaines the answers to the research question (RQ7). A total of twenty-eight methods have been proposed to solve research problems related to the detection of Plasmodium parasites. The dominant method in each literature is machine learning and deep learning algorithms, and one of which was support vector machine (SVM) with a total of nine kinds of literature. It is followed by conventional image processing methods by seven literature, embedded systems by three literature, and Convolutional Neural Network (CNN) by two literature. Meanwhile, the support vector machine (SVM) algorithm manages to provide excellent performance and machine learning algorithms such as K-Nearest Neighbors (KNN), K-Means Clustering, Naïve Bayes, Decision Tree, and Convolutional Neural Network (CNN). A complete list of performance of methods is shown in Table 6.

To determine the method that has the best performance, of course, many aspects should be taken into account. This issue remains a challenge for future research. When viewed from both machine learning and deep learning algorithms, as the most widely used algorithms today, each of these approaches has advantages and disadvantages. In addition, to apply machine learning and deep learning algorithms optimally, the researcher must recognize the characteristics of the problem that it faces because one of the characteristics of this approach is that there is no definite formulation for each problem case, or it is experimental. Therefore, the researcher must first analyze and recognize the object of research before deciding to use a suitable algorithm in solving the research problems.

If looked at the characteristics of the dataset, either public or private, both approaches have not outperformed each other. Each algorithm has advantages and disadvantages based on the cases that they are dealing with. For example, for a small 
number of datasets, machine learning algorithms should be used because the characteristics of this algorithm are designed for less complex datasets. This will also affect the computation time which tends to be faster even though the feature extraction and feature selection processes in machine learning are still done manually (hand-crafted feature selection). Also, the accuracy is plateaued in several methods that fall into this category such as support vector machine (SVM)., K-nearest neighbors (KNN), K-means clustering, Naïve Bayes, and decision tree.

However, if the case of the dataset is large, it is advisable to use a deep learning algorithm. This will be very identical to the resulting accuracy because deep learning is a very complex algorithm and is suitable for large-scale datasets, although it has an impact on long computation time. Nevertheless, the deep learning algorithm has carried out feature extraction and feature selection processes automatically (trainable feature extraction), and its accuracy is unlimited. Some examples of the methods in this category are convolutional neural networks (CNN) and artificial neural networks (ANN).

A study conducted by Devi [34] developed a classification of infected and uninfected erythrocytes by using three machine learning classification methods, namely SVM, k-NN, and Naive Bayes. The three methods were tested with the same dataset, namely 200 thin blood smears with the dimensions of $1500 \times 1000$ pixels, and there were 1300 erythrocytes. The results show that SVM has better accuracy performance by $98.38 \%$, while k-NN has $97.35 \%$, and Naïve Bayes has $97.23 \%$.

Some of the weaknesses of k-NN such as the need to determine the K parameter were susceptible to high dimensionality and sensitivity to outliers. However, k-NN was very strong in handling non-linear problems. Meanwhile, the Naïve Bayes method had several weaknesses including always assuming each independent variable. It reduces the accuracy because between one variable and another usually has a relationship, the accuracy cannot be measured with just one probability. However, Naïve Bayes has advantages such as not requiring a lot of data to conduct training and being able to perform binary classification or multiclass classification.

Although it has several weaknesses faced by both machine learning and deep learning as described previously, there is one method that demonstrates the most significant use by researchers at this time, especially in the field of detection of Plasmodium parasites. SVM is a machine learning algorithm that aims to perform classification and regression tasks. This method is very much implemented not only in the field of image processing but also in the field of computer vision. Additionally, the method is widely used in the fields of data mining, natural language processing (NLP), sentiment analysis, and so on.

The results that we obtained in this research were supported by one similar study conducted by Poostchi [13] in 2018. Poostchi [13] conducted a survey related to the trend of machine learning to detect malaria. It summarized the most widely used machine learning methods, one of which was the support vector machine (SVM). Meanwhile, based on the research of Cervantes [35] in 2019 who surveyed the SVM method, describes some of the advantages of SVM which made it widely used by researchers in the world today. According to Cervantes [35] the method was deemed to have a good theoretical basis and generalization capacity as well as be able to provide optimal solutions and discriminatory abilities.

Deep learning was known for its high degree of accuracy. Nonetheless, in comparison, it was found that SVM and deep learning on average had a similar performance or no significant difference. This claim was reinforced by research conducted by Bhowmik [36] and Sun [37] who argued that SVM had advantages and better performance than other machine learning methods.

\section{Conclusions}

This paper aims to analyze and identify research trends, methods, datasets, and performance of the methods used in the Plasmodium parasite automatic detection research between 2010 and 2019. Based on predetermined criteria (inclusion and exclusion) as well as some exceptions, such as title, abstract, and for the full text, forty-five significant pieces of literature were 
obtained related to the automatic detection of the Plasmodium parasite. In this paper, a literature review was conducted by nusing a systematic literature review according to the search from the last ten years. The results revealed that the type of publication in the field of research on the detection of parasitic Plasmodium was still dominated by journal articles.

The review collected twenty journal articles during the last ten years or equal to 59\%. Meanwhile, conference articles/proceedings included fourteen articles or $41 \%$. Plasmodium parasite research currently focused on three main topics, namely segmentation, detection, and classification. The total distribution of methods used in the discovery of Plasmodium parasites was $18 \%, 33 \%$, and $49 \%$ respectively. The use of private datasets was more dominant with a percentage of $89 \%$ covering as many as 40 pieces of literature out of a total of forty-five existing papers. Meanwhile, the use of public datasets only reached $11 \%$ or as much as five novels. Furthermore, the future research in the field of detection of Plasmodium parasites should focus on investigating the ways to overcome several differences which are considered as the weaknesses and strengths of each of the machine learning and deep learning algorithms.

The fundamental difference between machine learning and deep learning algorithms is the feature extraction process. When machine learning performs hand-crafted feature selection, deep learning does it automatically through trainable feature extraction. In addition, machine learning is more suitable for smaller datasets; the training process is faster, and the accuracy is plateauing. Meanwhile, deep learning requires a larger dataset and a long computation time. Therefore, to achieve good performance and overcome the weaknesses of machine learning and deep learning algorithms, some researchers in the field of detection of parasite Plasmodium are currently using an image processing approach and combining it with machine learning and deep learning algorithms. Additionally, a modification is required by carrying out the pre-processing stage first in order to improve or enhance image quality which is then combined with feature selection techniques and parameter optimization to produce better results.

\section{Acknowledgment}

This study is funded by Directorate General of Higher Education, Ministry of Research, Technology and Higher Education through the Research Grant of "Penelitian Dasar Unggulan Perguruan Tinggi". The authors would also like to thank Intelligent System research group in the Department of Electrical and Information Engineering, Universitas Gadjah Mada for inspiring discussion and motivation.

\section{Conflicts of Interest}

The authors declare no conflict of interest.

\section{References}

[1] F. Yang, M. Poostchi, H. Yu, Z. Zhou, K. Silamut, J. Yu, et al. "Deep Learning for Smartphone-Based Malaria Parasite Detection in Thick Blood Smears,” IEEE Journal of Biomedical and Health Informatics, vol. 24, no. 5, pp. 1427-1438, May 2020.

[2] H. A. Nugroho, W. A. Saputra, A. E. Permanasari, and E. E. H. Murhandarwati, "Automated Determination of Plasmodium Region of Interest on Thin Blood Smear Images," International Seminar on Intelligent Technology and Its Application (ISITIA), IEEE Press, August 2017, pp. 352-355.

[3] A. R. Bharti, K. P. Patra, R. Chuquiyauri, M. Kosek, R. H. Gilman, A. Llanos-Cuentas, et al., "Short Report: Polymerase Chain Reaction Detection of Plasmodium Vivax and Plasmodium Falciparum DNA from Stored Serum Samples: Implications for Retrospective Diagnosis of Malaria," The American Journal of Tropical Medicine and Hygiene, vol. 77, no. 3, pp. 444-446, September 2007.

[4] A. S. Abdul Nasir, M. Y. Mashor, and Z. Mohamed, "Segmentation Based Approach for Detection of Malaria Parasites Using Moving K-means Clustering," IEEE-EMBS Conference on Biomedical Engineering and Sciences, IEEE Press, December 2012, pp. 653-658. 
[5] H. A. Nugroho, A. F. D. Marsiano, K. Xaphakdy, P. Sihakhom, E. L. Frannita, R. Nurfauzi, et al. "Multithresholding Approach for Segmenting Plasmodium Parasites," International Conference on Information Technology and Electrical Engineering (ICITEE), IEEE, October 2019, pp. 1-5.

[6] A. H. Setianingrum, L. K. Wardhani, A. F. Ridwan, and S. F. Nasution, "Identification of Plasmodium Falciparum Stages Using Support Vector Machine Method," The 7th International Conference on Cyber and IT Service Management (CITSM), IEEE, November 2019, pp. 2-6.

[7] S. Nayak, S. Kumar, and M. Jangid, "Malaria Detection Using Multiple Deep Learning Approaches," 2nd International Conference on Intelligent Communication and Computational Techniques (ICCT), September 2019, pp. $292-297$.

[8] S. S. Prakash, B. C. Kovoor, and K. Visakha, "Convolutional Neural Network Based Malaria Parasite Infection Detection Using Thin Microscopic Blood Smear Samples," Second International Conference on Inventive Research in Computing Applications (ICIRCA), IEEE, July 2020, pp. 308-313.

[9] G. Shekar, S. Revathy, and E. K. Goud, "Malaria Detection Using Deep Learning," 4th International Conference on Trends in Electronics and Informatics (ICOEI), IEEE, June 2020, pp. 746-750.

[10] D. Shah, K. Kawale, M. Shah, S. Randive, and R. Mapari, "Malaria Parasite Detection Using Deep Learning: (Beneficial to Humankind)," International Conference on Intelligent Computing and Control Systems (ICICCS), IEEE, May 2020, pp. 984-988.

[11] L. Rosado, J. M. Correia da Costa, D. Elias, and J. S. Cardoso, “A Review of Automatic Malaria Parasites Detection and Segmentation in Microscopic Images,” Journals of Anti-Infective Agents, vol. 14, no. 1, pp. 11-22, March 2016.

[12] Z. Jan, A. Khan, M. Sajjad, K. Muhammad, S. Rho, and I. Mehmood, "A Review on Automated Diagnosis of Malaria Parasite in Microscopic Blood Smears Images,” Journals of Multimedia Tools and Appllications., vol. 77, no. 8, pp. 9801-9826, March 2018.

[13] M. Poostchi, K. Silamut, R. J. Maude, S. Jaeger, and G. Thoma, "Image Analysis and Machine Learning for Detecting Malaria,” Journals of Translational Research., vol. 194, pp. 36-55, April 2018.

[14] R. S. Wahono, "A Systematic Literature Review of Software Defect Prediction: Research Trends, Datasets, Methods and Frameworks," Journal of Software Engineering, vol. 1, no. 1, pp. 1-16, April 2015.

[15] S. Keele, "Guidelines for Performing Systematic Literature Reviews in Software Engineering," School of Computer Science and Mathematics, Keele University, EBSE Technical Report-2007-01, July 09, 2007.

[16] R. S. Wahono, "Systematic Literature Review: Pengantar, Tahapan Dan Studi Kasus" https://romisatriawahono.net/2016/05/15/systematic-literature-review-pengantar-tahapan-dan-studi-kasus, April 10, 2020.

[17] P. H. Prastyo, A. S. Sumi, and S. S. Kusumawardani, “A SystematicLliterature Review of Application Development to Realize Paperless Application in Indonesia: Sectors, Platforms, Impacts, and Challenges,” Indonesian Journal of Information System, vol. 2, no. 2, pp. 111-129, February 2020.

[18] E. V. H. S, M. Y. Mashor, A. S. A. Nasir, and H. Jaafar, "A Fast and Accurate Detection of Schizont Plasmodium Falciparum Using Channel Color Space Segmentation Method," 5th International Conference on Cyber and IT Service Management (CITSM), IEEE, August 2017, pp. 1-4.

[19] H. A. Nugroho, F. L. Tantowi, R. Anggara, TM. D Aldibra, R. Nurfauzi, E. L. Frannita, et al., "Segmentation of Plasmodium Using Saturation Channel of HSV Color Space," International Conference on Information and Communications Technology (ICOIACT), February 2019, pp. 91-94.

[20] M. M. Aladago, L. Torresani, E. V. Rosca, and A. Malaria, "Semantic Segmentation of The Growth Stages of Plasmodium Parasites Using Convolutional Neural Networks,” IEEE Africon Conference, IEEE, September 2019, pp. 1-7.

[21] A. Pinkaew, T. Limpiti, and A. Trirat, "Automated Classification of Malaria Parasite Species on Thick Blood Film Using Support Vector Machine,” The 2015 Biomedical Engineering International Conference (BMEiCON), IEEE, November 2015.

[22] H. A. Mohammed and I. A. M. Abdelrahman, "Detection and Classification of Malaria in Thin Blood Slide Images," International Conference on Communication, Control, Computing and Electronics Engineering (ICCCCEE), IEEE, January 2015, pp. 1-5.

[23] W. Kudisthalert, K. Pasupa, and S. Tongsima, "Counting and Classification of Malarial Parasite from Giemsa-stained Thin Film Images,” Journals and Megazines IEEE Access, vol. 8, pp. 78663-78682, April 2020.

[24] M. Elter, E. Hasslmeyer, and T. Zerfass, "Detection of Malaria Parasites in Thick Blood Films," Annual international conference of the IEEE Engineering in Medicine and Biology Society, IEEE Press, August 2011, pp. 5140-5144.

[25] D. K. Das, M. Ghosh, M. Pal, A. K. Maiti, and C. Chakraborty, "Machine Learning Approach for Automated Screening of Malaria Parasite Using Light Microscopic Images,” Micron, vol. 45, pp. 97-106, February 2013. 
[26] S. S. Savkare and S. P. Narote, "Blood Cell Segmentation from Microscopic Blood Images," International Conference on Information Processing (ICIP), IEEE Press, December 2015, pp. 502-505.

[27] W. Preedanan, M. Phothisonothai, W. Senavongse, and S. Tantisatirapong, "Automated Detection of Plasmodium Falciparum From Giemsa-stained Thin Blood Films," The 8th International Conference on Knowledge and Smart Technology (KST), IEEE Press, February 2016, pp. 215-218.

[28] Z. Zhang, L. S. Ong, K. Fang, A. Matthew, J. Dauwells. M. Dao, et al., "Image Classification of Unlabeled Malaria Parasites in Red Blood Cells," The 38th Annual International Conference of the IEEE Engineering in Medicine and Biology Society (EMBS), IEEE Press, August 2016, pp. 3981-3984.

[29] L. Rosado, J. M. C. Da Costa, D. Elias, and J. S. Cardoso, "Automated Detection of Malaria Parasites on Thick Blood Smears Via Mobile Devices,” Procedia Computer Science, vol. 90, pp. 138-144, July 2016.

[30] I. R. Dave, "Image Analysis for Malaria Parasite Detection from Microscopic Images of Thick Blood Smear," International Conference on Wireless Communications, Signal Processing and Networking (WiSPNET), IEEE Press, March 2017, pp. 1303-1307.

[31] A. R. Prananda, H. A. Nugroho, and I. Ardiyanto, "Enumeration of Plasmodium Parasites on Thin Blood Smear Digital Microscopic Images,"The 5th International Conference on Science in Information Technology (ICSITech), IEEE Press, October 2019, pp. 223-228.

[32] H. A. Nugroho, J. B. Abraham, A. H. Azzira, E. L. Frannita, R. Nurfauzi, F. M. Azif, et al., "Performance of Convolutional Neural Network in Detecting Plasmodium Parasites," The 9th International Conference on System Engineering and Technology (ICSET), IEEE Press, October 2019, pp. 331-336.

[33] A. Vijayalakshmi and B. Rajesh Kanna, "Deep Learning Approach to Detect Malaria from Microscopic Images," Journals of Multimedia Tools and Appllications, vol. 79, no. 21, pp. 15297-15317, January 2019.

[34] S. S. Devi, A. Roy, J. Singha, S. A. Sheikh, and R. H. Laskar, "Malaria Infected Erythrocyte Classification Based on A Hybrid Classifier Using Microscopic Images of Thin Blood Smear," Journals of Multimedia Tools and Appllications, vol. 77, no. 1, pp. 631-660, December 2018.

[35] J. Cervantes, F. Garcia-Lamont, L. Rodríguez-Mazahua, and A. Lopez, "A Comprehensive Survey on Support Vector Machine Classification: Applications, Challenges and Trends," Journals of Neurocomputing, vol. 408, pp. 189-215, September 2020.

[36] T. K. Bhowmik, P. Ghanty, A. Roy, and S. K. Parui, "SVM-Based Hierarchical Architectures for Handwritten Bangla Character Recognition," International Journal on Document Analysis and Recognition., vol. 12, no. 2, pp. 97-108, March 2009.

[37] B. Y. Sun, D. S. Huang, and H. T. Fang, "Lidar Signal Denoising Using Least-Squares Support Vector Machine," IEEE Signal Processing Letters, vol. 12, no. 2, pp. 101-104, February 2005.

Copyright $\bigcirc$ by the authors. Licensee TAETI, Taiwan. This article is an open access article distributed under the terms and conditions of the Creative Commons Attribution (CC BY-NC) license (http://creativecommons.org/licenses/by/4.0/). 